\title{
X-ray powder diffraction analysis of a silver(I)-aspartame complex
}

\author{
R. Putvinskis and C. O. Paiva-Santos \\ Laboratório Computacional de Análises Cristalográficas e Cristalinas - LabCACC, Instituto de Química, \\ UNESP, 14800-900, Rua Prof. Francisco Degni s/n, Araraquara, SP, Brazil \\ M. Cavicchioli and A. C. Massabni \\ Departamento de Química Geral e Inorgânica, Instituto de Química, UNESP, 14800-900, Rua Prof. \\ Francisco Degni s/n, Araraquara, SP, Brazil
}

(Received 30 May 2006; accepted 10 October 2006)

\begin{abstract}
Synchrotron X-ray powder diffraction (XRPD) data were collected for the silver(I)-aspartame complex $\left[\mathrm{Ag}\left(\mathrm{C}_{14} \mathrm{H}_{17} \mathrm{~N}_{2} \mathrm{O}_{5}\right)\right] \cdot 1 / 2 \mathrm{H}_{2} \mathrm{O}$. The complex was obtained from a stoichiometric mixture of aspartame (3-amino- $\mathrm{N}$ - $\left(\alpha\right.$-carboxyphenethyl)-succinamic acid $\mathrm{N}$-methyl ester, $\left.\mathrm{C}_{14} \mathrm{H}_{18} \mathrm{~N}_{2} \mathrm{O}_{5}\right)$, $\mathrm{Na}_{2} \mathrm{CO}_{3}$, and $\mathrm{AgNO}_{3}$. Indexing using Crysfire and Chekcell proposed an orthorhombic unit cell with space group $P 222_{1}$. The lattice parameters are $a=12.4750(1) \AA, b=21.60614(14) \AA$, and $c$ =4.88888(9) А. (C) 2006 International Centre for Diffraction Data. [DOI: 10.1154/1.2383065]
\end{abstract}

Key words: silver(I)-aspartame, X-ray diffraction, Le Bail method

\section{INTRODUCTION}

Silver and several of its compounds have been used as antimicrobial agents in medicine (Klasen, 2000a, b; De Gracia, 2001; Modak et al., 1983; Nomiya et al., 1995, 1997; Nomiya and Yokoyama, 2002). Silver(I)-sulfadiazine has been used clinically as an antimicrobial and antifungical agent. It is an insoluble polymeric compound that releases $\mathrm{Ag}(\mathrm{I})$ ions slowly, and it is applied topically as a cream to prevent bacterial infections in cases of severe burns.

Aspartame (3-amino- $\mathrm{N}-(\alpha$-carboxyphenethyl)-succinamic acid $\mathrm{N}$-methyl ester, $\mathrm{C}_{14} \mathrm{H}_{18} \mathrm{~N}_{2} \mathrm{O}_{5}$ ) is a compound used as a commercial sweetener (Figure 1). In general, sweeteners have functional groups like carbonyl, carboxylate, amino, and sulfamate, which allow them to be used as ligands in coordination and bioinorganic chemistry. The complexes formed with aspartame as ligand could have low toxicity for the human body and could be used as a pharmaceutical product.

Because silver compounds have antibacterial properties and aspartame has low toxicity and low manufacturing costs, a silver(I)-aspartame complex was obtained in our laboratory. In fact, the compound reported in this paper showed a potent antimicobacterial activity against species of mycobacteria, including Mycobacterium tuberculosis, which is responsible for tuberculosis infection. The other species tested were Mycobacterium avium, Mycobacterium intracellulare, Mycobacterium malmoense, and Mycobacterium kansaii.

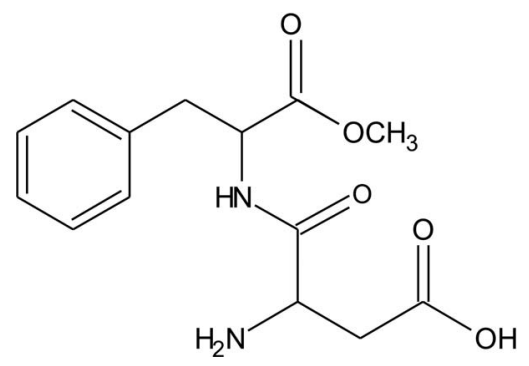

Figure 1. Schematic representation of aspartame.
The aim of the present work is to characterize the silver(I)-aspartame complex using a collection of techniques including X-ray powder diffraction.

\section{EXPERIMENTAL}

Aspartame was obtained from Monsanto, sodium carbonate from Sigma, and silver(I) nitrate from Acros Organics as analytical grade purity.

To synthesize the silver(I)-aspartame complex $\left[\mathrm{Ag}\left(\mathrm{C}_{14} \mathrm{H}_{17} \mathrm{~N}_{2} \mathrm{O}_{5}\right)\right] \cdot 1 / 2 \mathrm{H}_{2} \mathrm{O}$, an aqueous solution of $\mathrm{AgNO}_{3}$ $(0.340 \mathrm{~g}, 2.0 \mathrm{mmol})$ was added to a solution containing $0.590 \mathrm{~g}(2.0 \mathrm{mmol})$ of aspartame and $0.106 \mathrm{~g}(1.0 \mathrm{mmol})$ of $\mathrm{Na}_{2} \mathrm{CO}_{3}$ under stirring. A white crystalline powder of the complex was obtained. The compound was washed with $\sim 200 \mathrm{~mL}$ of water and dried over $\mathrm{P}_{4} \mathrm{O}_{10}$ under vacuum.

Elemental analysis of carbon, hydrogen, and nitrogen was performed using a CHNS-O EA1110 Analyzer, CE Instruments. High purity cysteine was used as a reference sub-

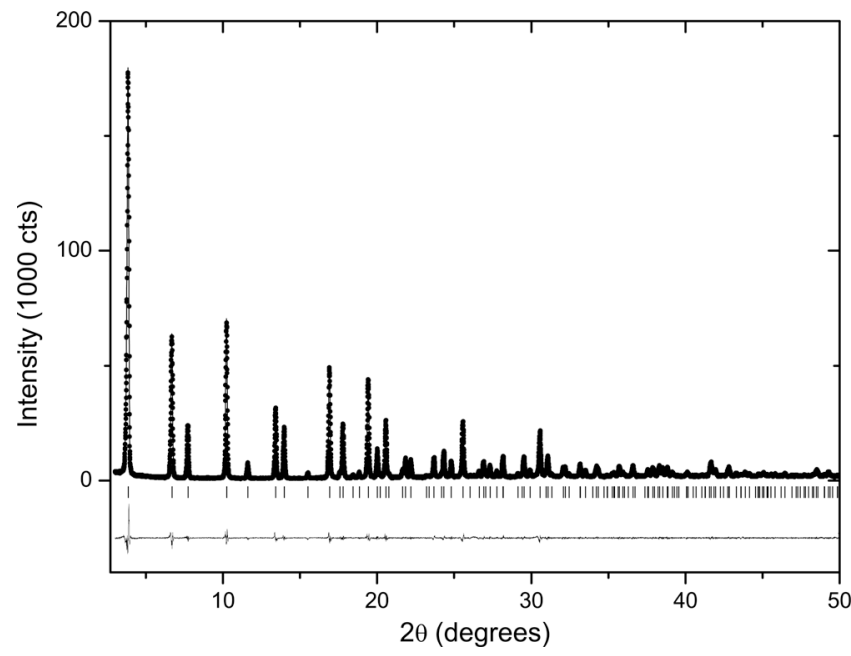

Figure 2. Observed (dots), calculated (continuous line), and difference (bottom line) diffractograms for silver(I)-aspartame. The small vertical lines above the difference plot indicate the Bragg peak positions. 
TABLE I. Unit cell parameters before and after the Le Bail fit, for $\left[\mathrm{Ag}\left(\mathrm{C}_{14} \mathrm{H}_{17} \mathrm{~N}_{2} \mathrm{O}_{5}\right)\right] \cdot \frac{1}{2} \mathrm{H}_{2} \mathrm{O}$.

\begin{tabular}{lcccc}
\hline \hline & Space group & $\mathrm{a}(\AA)$ & $\mathrm{b}(\AA)$ & $\mathrm{c}(\AA)$ \\
\hline $\begin{array}{l}\text { after Crysfire } \\
\text { after Le Bail refinement }\end{array}$ & $P 222_{1}$ & 12.472 & 21.603 & 4.887 \\
\hline \hline
\end{tabular}

stance. Silver content was determined by atomic absorption using a Perkin Elmer instrument. The infrared spectrum was recorded on a Spectrum 2000 FT-IR Perkin Elmer spectrophotometer. Sample was prepared as $\mathrm{KBr}$ pellets.

Synchrotron X-ray diffraction data were obtained, and the experimental setup consisted of a $\mathrm{Si}(111)$ double crystal monochromator with the first crystal refrigerated and the second sagitally curved. A scintillation detector was used. The monochromator was adjusted to select energy $\mathrm{E}$ $=8.4995 \mathrm{keV}(\lambda=1.45864 \AA)$, which is the energy close to the maximum flux at the Laboratório Nacional de Luz Síncrotron (LNLS)-Brazil. The sample was deposited in a plane sample holder of $10 \times 12 \mathrm{~mm}^{2}$. Data were collected from 3 to $50^{\circ} 2 \theta$, with a step scan of $0.005^{\circ} 2 \theta$. The software XFit (Coelho and Cheary, 1997) was used to fit 36 peaks that were used in the indexation with the Crysfire suite (Shirley, 2002). $\mathrm{A} \mathrm{Y}_{2} \mathrm{O}_{3}$ sample was used as an external standard to check the wavelength and instrumental broadening.

\section{RESULTS AND DISCUSSION}

The silver(I)-aspartame complex has the formula $\left[\mathrm{Ag}\left(\mathrm{C}_{14} \mathrm{H}_{17} \mathrm{~N}_{2} \mathrm{O}_{5}\right)\right] \cdot 1 / 2 \mathrm{H}_{2} \mathrm{O}$, according to the analysis of $\mathrm{C}$, $\mathrm{H}, \mathrm{N}$, and $\mathrm{Ag}$. The experimentally measured weight concentrations are $\mathrm{C} 41.0 \%, \mathrm{H} 4.93 \%, \mathrm{~N} 6.11 \%$, and $\mathrm{Ag} 26.5 \%$, which are in good agreement with the theoretically calculated concentrations of C $41.9 \%, \mathrm{H} 4.27 \%, \mathrm{~N} 6.97 \%$, and $\mathrm{Ag}$ $26.8 \%$.

Main IR features of aspartame are $3324 \mathrm{~cm}^{-1}$ (s, $\nu \mathrm{N}-\mathrm{H}$ of $\left.\mathrm{NH}_{2}\right), 3066-2850 \mathrm{~cm}^{-1}(\mathrm{~s}, \nu \mathrm{C}-\mathrm{H}$ of the aromatic ring and aliphatic chain), $1738 \mathrm{~cm}^{-1}(\mathrm{~s}, \nu \mathrm{C}=\mathrm{O}$ of the ester), $1666 \mathrm{~cm}^{-1}$ (s, $\nu \mathrm{C}=\mathrm{O}$ of the carboxylic group), $1588 \mathrm{~cm}^{-1}$ (s, $\nu \mathrm{C}=\mathrm{C}$ of the aromatic ring), $1547 \mathrm{~cm}^{-1}(\mathrm{~s}, \delta \mathrm{N}-\mathrm{H}$, scissoring of $\left.\mathrm{NH}_{2}\right), 1498 \mathrm{~cm}^{-1}$ (m, $\delta \mathrm{C}-\mathrm{H}$ of the aromatic ring), $1446 \mathrm{~cm}^{-1}$ (m, $\delta \mathrm{C}-\mathrm{O}-\mathrm{H}$ of the carboxylic group), $1379 \mathrm{~cm}^{-1}$ (s, $\nu \mathrm{C}-\mathrm{O}$ of the carboxylic group), and $1227 \mathrm{~cm}^{-1}$ (m, $\nu$ C-O of the ester) (Silverstein et al., 1991). IR features of the silver(I) complex differ from those of the free aspartame with respect to the position and profile of some bands indicating the participation of the corresponding groups in the coordination to the silver(I) cations. A strong broad band at $3434 \mathrm{~cm}^{-1}$ is related to the $\mathrm{O}-\mathrm{H}$ stretching of the hydration water molecules. The $\mathrm{C}-\mathrm{O}-\mathrm{Ag}$ bending and $\mathrm{C}-\mathrm{O}$ stretching bands of the carboxylate group are located at 1461 and $1394 \mathrm{~cm}^{-1}$, respectively, because of the monodentate coordination of the carboxylate group to silver(I) and consequent substitution of hydrogen by silver(I). Modifications are also observed in the $\mathrm{NH}_{2}$ bending band ( 1547 to $1575 \mathrm{~cm}^{-1}$ ), suggesting the coordination of silver(I) through the $\beta$-amino group. A thermogravimetric curve shows a weight loss at $393 \mathrm{~K}$, which corresponds to a half of a hydration water molecule loss.

Density measurements (pycnometric determination under helium, after a careful evacuation) permitted us to determine the experimental density, which is $\delta=1.2956 \mathrm{~g} / \mathrm{cm}^{3}$. This value is around $60 \%$ of the XRD density $(\delta x=\delta / 0.6$ $\left.=2.159 \mathrm{~g} / \mathrm{cm}^{-3}\right)$. This experimental value, combined with the molar mass of the complex, permitted us to calculate the number of formula units $Z$ in a cell $(Z=4)$.

By using the Crysfire suite, one solution with space group $P 222_{1}$ was found (by the program Chekcell, as listed in Table I). The solution was used for the Le Bail fit using the GSAS suite. The GSAS suite program (Larson and Von Dreele, 2001) was used for calculations. A pseudo-Voigt function was used as the profile function. During the refinement, only the profile parameters that varied with sec $\theta$ and $\operatorname{tg} \theta$ were refined, including the anisotropic strain parameters defined by Stephens (1999).

The final lattice parameters after the refinement are also listed in Table I. Peak intensities and Miller indexes are given in Table II. The observed, calculated, and difference diffractograms are plotted in Figure 2.

TABLE II. Powder X-ray diffraction data for Ag-aspartame.

\begin{tabular}{|c|c|c|c|c|c|c|c|c|c|}
\hline $\mathrm{h}$ & $\mathrm{k}$ & 1 & d & I100 & $\mathrm{h}$ & $\mathrm{k}$ & 1 & d & I100 \\
\hline 0 & 1 & 0 & 21.606 & 100 & 1 & 6 & 1 & 2.824 & 1 \\
\hline 1 & 0 & 0 & 12.475 & 31 & 2 & 7 & 0 & 2.766 & 12 \\
\hline 1 & 1 & 0 & 10.804 & 7 & 3 & 6 & 0 & 2.722 & 5 \\
\hline 0 & 2 & 0 & 10.803 & 3 & 3 & 4 & 1 & 2.732 & $<1$ \\
\hline 1 & 2 & 0 & 8.167 & 33 & 4 & 4 & 0 & 2.701 & $<1$ \\
\hline 0 & 3 & 0 & 7.202 & 3 & 0 & 8 & 0 & 2.701 & $<1$ \\
\hline 1 & 3 & 0 & 6.237 & 10 & 1 & 8 & 0 & 2.640 & 2 \\
\hline 2 & 0 & 0 & 6.238 & 5 & 0 & 7 & 1 & 2.610 & $<1$ \\
\hline 2 & 1 & 0 & 5.993 & 10 & 4 & 0 & 1 & 2.629 & $<1$ \\
\hline 2 & 2 & 0 & 5.402 & $<1$ & 2 & 6 & 1 & 2.629 & 1 \\
\hline 0 & 4 & 0 & 5.402 & $<1$ & 4 & 1 & 1 & 2.610 & $<1$ \\
\hline 1 & 4 & 0 & 4.957 & 24 & 3 & 5 & 1 & 2.555 & 1 \\
\hline 0 & 1 & 1 & 4.769 & 1 & 1 & 7 & 1 & 2.555 & 1 \\
\hline
\end{tabular}


TABLE II. (Continued.)

\begin{tabular}{|c|c|c|c|c|c|c|c|c|c|}
\hline $\mathrm{h}$ & $\mathrm{k}$ & 1 & d & I100 & $\mathrm{h}$ & $\mathrm{k}$ & 1 & d & I100 \\
\hline 2 & 3 & 0 & 4.715 & 12 & 4 & 2 & 1 & 2.555 & 1 \\
\hline 1 & 0 & 1 & 4.552 & $<1$ & 4 & 5 & 0 & 2.529 & 1 \\
\hline 1 & 1 & 1 & 4.454 & $<1$ & 5 & 0 & 0 & 2.495 & $<1$ \\
\hline 0 & 2 & 1 & 4.454 & $<1$ & 5 & 1 & 0 & 2.479 & $<1$ \\
\hline 0 & 5 & 0 & 4.321 & 22 & 3 & 7 & 0 & 2.478 & $<1$ \\
\hline 1 & 2 & 1 & 4.195 & 5 & 2 & 8 & 0 & 2.478 & $<1$ \\
\hline 3 & 0 & 0 & 4.158 & $<1$ & 4 & 3 & 1 & 2.470 & 1 \\
\hline 3 & 1 & 0 & 4.083 & 4 & 5 & 2 & 0 & 2.431 & $<1$ \\
\hline 2 & 4 & 0 & 4.083 & 4 & 0 & 0 & 2 & 2.445 & $<1$ \\
\hline 1 & 5 & 0 & 4.083 & 4 & 0 & 1 & 2 & 2.429 & $<1$ \\
\hline 0 & 3 & 1 & 4.045 & $<1$ & 2 & 7 & 1 & 2.408 & $<1$ \\
\hline 3 & 2 & 0 & 3.881 & 1 & 0 & 9 & 0 & 2.401 & $<1$ \\
\hline 1 & 3 & 1 & 3.848 & 2 & 0 & 2 & 2 & 2.384 & $<1$ \\
\hline 2 & 0 & 1 & 3.848 & 1 & 1 & 0 & 2 & 2.399 & $<1$ \\
\hline 2 & 1 & 1 & 3.788 & 3 & 3 & 6 & 1 & 2.378 & 2 \\
\hline 0 & 4 & 1 & 3.625 & $<1$ & 1 & 1 & 2 & 2.384 & $<1$ \\
\hline 3 & 3 & 0 & 3.601 & $<1$ & 4 & 4 & 1 & 2.364 & $<1$ \\
\hline 0 & 6 & 0 & 3.601 & $<1$ & 0 & 8 & 1 & 2.364 & $<1$ \\
\hline 2 & 2 & 1 & 3.625 & $<1$ & 5 & 3 & 0 & 2.358 & $<1$ \\
\hline 2 & 5 & 0 & 3.552 & 4 & 4 & 6 & 0 & 2.358 & $<1$ \\
\hline 1 & 4 & 1 & 3.481 & $<1$ & 1 & 9 & 0 & 2.357 & $<1$ \\
\hline 1 & 6 & 0 & 3.460 & 6 & 1 & 2 & 2 & 2.342 & $<1$ \\
\hline 2 & 3 & 1 & 3.394 & 3 & 1 & 8 & 1 & 2.323 & 2 \\
\hline 3 & 4 & 0 & 3.295 & 13 & 0 & 3 & 2 & 2.315 & $<1$ \\
\hline 0 & 5 & 1 & 3.238 & $<1$ & 3 & 8 & 0 & 2.265 & $<1$ \\
\hline 3 & 0 & 1 & 3.168 & 1 & 1 & 3 & 2 & 2.276 & $<1$ \\
\hline 2 & 4 & 1 & 3.134 & 1 & 5 & 4 & 0 & 2.265 & $<1$ \\
\hline 1 & 5 & 1 & 3.134 & 1 & 2 & 0 & 2 & 2.276 & $<1$ \\
\hline 4 & 0 & 0 & 3.119 & $<1$ & 2 & 9 & 0 & 2.240 & $<1$ \\
\hline 2 & 6 & 0 & 3.119 & $<1$ & 2 & 1 & 2 & 2.263 & $<1$ \\
\hline 3 & 1 & 1 & 3.134 & 1 & 4 & 5 & 1 & 2.246 & 2 \\
\hline 4 & 1 & 0 & 3.087 & 1 & 0 & 4 & 2 & 2.227 & $<1$ \\
\hline 0 & 7 & 0 & 3.087 & $<1$ & 5 & 0 & 1 & 2.222 & 2 \\
\hline 3 & 2 & 1 & 3.040 & 1 & 2 & 2 & 2 & 2.227 & $<1$ \\
\hline 3 & 5 & 0 & 2.996 & 1 & 5 & 1 & 1 & 2.211 & $<1$ \\
\hline 4 & 2 & 0 & 2.996 & 1 & 3 & 7 & 1 & 2.211 & $<1$ \\
\hline 1 & 7 & 0 & 2.996 & 1 & 2 & 8 & 1 & 2.211 & $<1$ \\
\hline 3 & 3 & 1 & 2.900 & $<1$ & 4 & 7 & 0 & 2.194 & 1 \\
\hline 0 & 6 & 1 & 2.899 & $<1$ & 1 & 4 & 2 & 2.192 & $<1$ \\
\hline 4 & 3 & 0 & 2.862 & 4 & 5 & 2 & 1 & 2.177 & $<1$ \\
\hline 2 & 5 & 1 & 2.874 & $<1$ & 5 & 5 & 0 & 2.161 & $<1$ \\
\hline 0 & 10 & 0 & 2.161 & $<1$ & 5 & 6 & 1 & 1.891 & $<1$ \\
\hline 2 & 3 & 2 & 2.170 & $<1$ & 4 & 8 & 1 & 1.884 & $<1$ \\
\hline 0 & 9 & 1 & 2.155 & $<1$ & 2 & 10 & 1 & 1.884 & $<1$ \\
\hline 1 & 10 & 0 & 2.129 & $<1$ & 4 & 2 & 2 & 1.894 & $<1$ \\
\hline 0 & 5 & 2 & 2.128 & $<1$ & 3 & 5 & 2 & 1.894 & $<1$ \\
\hline 5 & 3 & 1 & 2.124 & $<1$ & 1 & 7 & 2 & 1.894 & $<1$ \\
\hline 4 & 6 & 1 & 2.124 & $<1$ & 6 & 5 & 0 & 1.874 & $<1$ \\
\hline 1 & 9 & 1 & 2.123 & $<1$ & 2 & 11 & 0 & 1.873 & $<1$ \\
\hline 2 & 4 & 2 & 2.097 & $<1$ & 6 & 2 & 1 & 1.884 & $<1$ \\
\hline 1 & 5 & 2 & 2.097 & $<1$ & 6 & 3 & 1 & 1.849 & $<1$ \\
\hline 3 & 0 & 2 & 2.107 & $<1$ & 4 & 3 & 2 & 1.859 & $<1$ \\
\hline 3 & 9 & 0 & 2.079 & $<1$ & 5 & 8 & 0 & 1.833 & $<1$ \\
\hline 3 & 1 & 2 & 2.097 & $<1$ & 0 & 11 & 1 & 1.823 & $<1$ \\
\hline 6 & 1 & 0 & 2.070 & $<1$ & 2 & 7 & 2 & 1.832 & $<1$ \\
\hline 6 & 0 & 0 & 2.079 & $<1$ & 0 & 8 & 2 & 1.812 & $<1$ \\
\hline 3 & 2 & 2 & 2.068 & $<1$ & 3 & 6 & 2 & 1.819 & $<1$ \\
\hline 3 & 8 & 1 & 2.055 & $<1$ & 6 & 4 & 1 & 1.804 & $<1$ \\
\hline 5 & 6 & 0 & 2.051 & 4 & 5 & 7 & 1 & 1.804 & $<1$ \\
\hline 5 & 4 & 1 & 2.055 & $<1$ & 1 & 11 & 1 & 1.803 & $<1$ \\
\hline
\end{tabular}




\begin{tabular}{|c|c|c|c|c|c|c|c|c|c|}
\hline $\mathrm{h}$ & $\mathrm{k}$ & 1 & d & I100 & $\mathrm{h}$ & $\mathrm{k}$ & 1 & d & I100 \\
\hline 6 & 2 & 0 & 2.042 & $<1$ & 4 & 4 & 2 & 1.812 & $<1$ \\
\hline 4 & 8 & 0 & 2.042 & $<1$ & 6 & 6 & 0 & 1.801 & $<1$ \\
\hline 2 & 10 & 0 & 2.042 & $<1$ & 0 & 12 & 0 & 1.801 & $<1$ \\
\hline 2 & 9 & 1 & 2.037 & 1 & 1 & 8 & 2 & 1.794 & $<1$ \\
\hline 3 & 3 & 2 & 2.023 & $<1$ & 4 & 10 & 0 & 1.776 & $<1$ \\
\hline 0 & 6 & 2 & 2.023 & $<1$ & 3 & 11 & 0 & 1.776 & $<1$ \\
\hline 4 & 7 & 1 & 2.002 & $<1$ & 3 & 10 & 1 & 1.785 & $<1$ \\
\hline 2 & 5 & 2 & 2.014 & $<1$ & 7 & 0 & 0 & 1.782 & $<1$ \\
\hline 6 & 3 & 0 & 1.998 & $<1$ & 1 & 12 & 0 & 1.782 & $<1$ \\
\hline 1 & 6 & 2 & 1.996 & 1 & 7 & 1 & 0 & 1.776 & $<1$ \\
\hline 5 & 5 & 1 & 1.976 & $<1$ & 4 & 9 & 1 & 1.773 & 1 \\
\hline 0 & 10 & 1 & 1.976 & $<1$ & 7 & 2 & 0 & 1.758 & $<1$ \\
\hline 0 & 11 & 0 & 1.964 & $<1$ & 6 & 5 & 1 & 1.750 & $<1$ \\
\hline 1 & 10 & 1 & 1.952 & 1 & 2 & 11 & 1 & 1.749 & $<1$ \\
\hline 3 & 4 & 2 & 1.963 & $<1$ & 4 & 5 & 2 & 1.758 & $<1$ \\
\hline 6 & 4 & 0 & 1.940 & $<1$ & 3 & 7 & 2 & 1.740 & $<1$ \\
\hline 5 & 7 & 0 & 1.940 & $<1$ & 2 & 8 & 2 & 1.740 & $<1$ \\
\hline 1 & 11 & 0 & 1.940 & $<1$ & 5 & 9 & 0 & 1.730 & $<1$ \\
\hline 3 & 10 & 0 & 1.917 & $<1$ & 2 & 12 & 0 & 1.730 & $<1$ \\
\hline 3 & 9 & 1 & 1.913 & $<1$ & 5 & 0 & 2 & 1.746 & $<1$ \\
\hline 4 & 0 & 2 & 1.924 & $<1$ & 6 & 7 & 0 & 1.724 & $<1$ \\
\hline 2 & 6 & 2 & 1.924 & $<1$ & 5 & 1 & 2 & 1.740 & $<1$ \\
\hline 4 & 1 & 2 & 1.916 & $<1$ & 7 & 3 & 0 & 1.730 & 1 \\
\hline 0 & 7 & 2 & 1.916 & $<1$ & 5 & 8 & 1 & 1.716 & 4 \\
\hline 4 & 9 & 0 & 1.902 & $<1$ & 5 & 2 & 2 & 1.724 & $<1$ \\
\hline 6 & 0 & 1 & 1.913 & $<1$ & 0 & 9 & 2 & 1.713 & 2 \\
\hline 6 & 1 & 1 & 1.906 & $<1$ & & & & & \\
\hline
\end{tabular}

\section{CONCLUSION}

The silver(I)-aspartame complex was obtained, which presents a potent antimicobacterial activity against species of mycobacteria, including Mycobacterium tuberculosis. The formula of the complex, determined by elemental analysis, is $\left[\mathrm{Ag}\left(\mathrm{C}_{14} \mathrm{H}_{17} \mathrm{~N}_{2} \mathrm{O}_{5}\right)\right] \cdot 1 / 2 \mathrm{H}_{2} \mathrm{O}$. The silver(I)-aspartame complex presents orthorhombic symmetry with unit cell parameters $a=12.4750(1) \AA, \quad b=21.60614(14) \AA$, and $c$ $=4.888$ 89(9) $\AA$ with space group $P 222_{1}$.

\section{ACKNOWLEDGMENTS}

The authors are grateful to Fundação de Amparo à Pesquisa do Estado de São Paulo (FAPESP) and Conselho Nacional de Desenvolvimento Cientifico e Tecnológico (CNPq) for financial support.

Coelho, A. A. and Cheary, R. W. (1997). "X-ray Line Profile Fitting Program, XFIT," School of Physical Sciences, University of Technology, Sydney, New South Wales, Australia.

De Gracia, C. G. (2001). "An open study comparing topical silver sulfadiazine and topical silver sulfadiazine-cerium nitrate in the treatment of moderate and sever burns," Burns 27, 67-74.

Klasen, H. J. (2000a). "Historical review of the use of silver in the treatment of burns, I. Early uses," Burns 26, 117-130.

Klasen, H. J. (2000b). "A historical review of the use of silver in the treatment of burns, II. Renewed interest for silver," Burns 26, 131-138.

Larson, A. C. and Von Dreele, R. B. (2001). "GSAS-General Structure Analysis System," Los Alamos National Laboratory. Los Alamos, EUA. Copyright 1985-2000, The Regents of the University of California.

Modak, S., Stanford, J., Friendlaender, J., Fox, P., and Fox, C. L., (1983). "Control of burn wound infections by pentafloxacin and its silver derivative," Burns 10, 170-178.

Nomiya, K., Kondoh, Y., Onoue, K., Kasuga, N. C., Nagano, H., Oda, M., Sudoh, T., and Sakuma, S. (1995). "Synthesis and characterization of polymeric, anionic thiosalicylato- $\mathrm{Ag}(\mathrm{I})$ complexes with antimicrobial activities," J. Inorg. Biochem. 58, 255-267.

Nomiya, K., Tsuda, K., Sudoh, T., and Oda, M. (1997). "Ag(I)-N bondcontaining compound showing wide spectra in effective antimicrobial activities: polymeric silver(I) imidazolate," J. Inorg. Biochem. 68, 3944.

Nomiya, K. and Yokoyama, H. (2002). "Synthesis, crystal structures and antimicrobial activities of polymeric silver(I) complexes with three amino-acids [aspartic acid ( $\left.\mathrm{H}_{2} \mathrm{asp}\right)$, glycine (Hgly) and asparagine (Hasn)]," J. Chem. Soc. Dalton Trans. 12, 2483-2490.

Shirley, R. (2002). The Crysfire 2002 System for Automatic Powder Indexing: User's Manual (Lattice, Guildford, England).

Silverstein, R. M., Bassler, G. C., and Morrill, T. C. (1991). Spectrometric Identification of Organic Compounds 5th ed. (Wiley, Singapore).

Stephens, P. W. (1999). "Phenomenological model of anisotropic peak broadening in powder diffraction," J. Appl. Crystallogr. 32, 281-289. 